\title{
Judicialização antes da democratização? O Supremo Tribunal Federal e o destino da Emenda Constitucional das "Diretas Já"
}

\author{
Judicialization before democratization: The Supreme Court and the fate of the \\ "Diretas Já" amendment
}

\author{
Diego Werneck Arguelhes* \\ Evandro Proença Süssekind ${ }^{* *}$
}

\section{Resumo}

\begin{abstract}
Este trabalho recupera a discussão sobre o papel do Supremo Tribunal Federal (STF) na rejeição da Proposta de Emenda Constitucional Dante de Oliveira - a Emenda das "Diretas Já" -, utilizando esse episódio para repensar a relação entre democratização e judicialização da política no Brasil. A participação do STF não integra a narrativa pública sobre a Emenda, nem os estudos acadêmicos sobre a transição para a democracia. A atuação do STF, porém, foi decisiva para o fracasso da reforma constitucional que viabilizaria as eleições diretas para a presidência da república. Neste trabalho, procuramos reconstruir a decisão das "Diretas Já" como um episódio de judicialização da política antes da democratização, com o Tribunal agindo sobre um conflito político de alta magnitude e recriando e justificando novas estruturas normativas no nível constitucional. Provocado por parlamentares do PMDB, o Supremo interveio no debate sobre como interpretar o quórum constitucional para aprovação de emendas. O Tribunal resolveu o conflito político a partir de argumentos constitucionais, afirmando, todo momento, a sua autoridade para resolver a questão. Embora tenha decidido em favor do governo militar, exerceu atividade criativa para fazê-lo, afastando-se de seus claros precedentes sobre o tema. Nesse sentido, como um episódio de judicialização da política antes da democratização, o caso das "Diretas Já" permite repensar, de forma mais precisa, a relação entre a democratização e os processos de expansão do poder do STF desde a transição.
\end{abstract}

Palavras-chave: "Diretas Já". Processo Legislativo. Emenda Constitucional. Supremo Tribunal Federal. Judicialização da política.

\section{Abstract}

In this paper, we analyze the Supreme Federal Court's (STF) role in the failure of the "Dante de Oliveira" constitutional amendment proposal in Congress - the "Diretas Já" amendment -, using this episode to challenge the relationship between democratization and the judicialization of politics in Brazil. Although official discourse and mainstream scholarship on the transition to democracy do not account for the STF's role in this regard, the court's intervention was consequential in the rejection of the amendment that would have otherwise established direct presidential elections in Brazil in the mid-80s. We reconstruct that judicial decision as an episode of "judicialization of politics" before democratization. An opposition political party triggered the court's jurisdiction, and the judges intervened on a debate about the right interpretation of constitutional procedural requirements that were decisive for the fate of the "Diretas Já" amendment. They did so by affirming, at all times, that the court had the authority to solve this political conflict, now transformed into a constitutional one, even as they also employed this power to decide in a way that was favorable to the military government. As an episode of judicialization of politics before the transition to democracy, then, this case poses broader questions on the precise relationship between democratization and the process of expansion of judicial power we have observed in Brazil in the last couple decades.

Keywords: "Diretas Já" amendment proposal. Legislative process. Constitutional amendment. Brazilian Supreme Court. Judicialization of politics.

Doutor em Direito e LL.M. pela Universidade Yale, EUA. Professor Adjunto, FGV Direito Rio. Bacharel e Mestre em Direito Público pela UERJ. Rio de Janeiro - RJ- Brasil. E-mail: dwarguelhes@gmail.com.

Mestre em Ciência Política pelo IESP/UERJ. Pesquisador assistente, FGV Direito Rio. Rio de Janeiro - RJ- Brasil. E-mail: e.p.sussekind@gmail.com. 


\section{Introdução}

É incontroverso afirmar que o poder do Supremo Tribunal Federal (STF) é, hoje, muito maior do que antes da democratização, e que a Constituição de 1988 foi um marco na expansão dos poderes da instituição para atuar junto à política. Com freqüência, a nova constituição aparece como um divisor de águas, antes do qual teríamos, talvez, uma "pré-história" da judicialização da política no Brasil. ${ }^{1}$ Neste trabalho, porém, discutiremos um caso em que, ainda durante o regime militar e com claros impactos no contexto nacional de busca de caminhos para viabilizar a transição para a democracia, o Supremo Tribunal Federal (STF) resolveu um conflito político decisivo por meio de interpretação constitucional.

O objetivo é recuperar a discussão sobre o papel do STF na rejeição da Proposta de Emenda Constitucional Dante de Oliveira - a Emenda das "Diretas Já" -, utilizando esse episódio para repensar a relação entre democratização e judicialização da política no Brasil. A participação do STF não integra nem a narrativa oficial sobre a Emenda, nem os estudos acadêmicos sobre a transição para a democracia. A atuação do Supremo, porém, foi decisiva para o fracasso da reforma constitucional que viabilizaria as eleições diretas para a presidência da república. Provocado por parlamentares do PMDB, o Supremo interveio no debate para, então, resolver o conflito político a partir de argumentos constitucionais, afirmando todo momento a sua autoridade para resolver aquele conflito político, agora convertido em uma questão de interpretação jurídica.

Neste trabalho, por meio de um estudo de caso da decisão, levantaremos implicações relevantes para o debate teórico nacional sobre judicialização da política - em especial, por ter ocorrido antes da promulgação da Constituição de 1988 e do encerramento (ao menos formal) do ciclo da transição para a democracia. O fenômeno da "judicialização da política" vem sendo definido de muitas maneiras diferentes. ${ }^{2}$ Entendido como a expansão da competência e da autoridade de tribunais e juízes para decidir questões políticas e de políticas públicas, antes limitadas ao processo decisório nos poderes eleitos, a democratização e/ou consolidação democrática tem sido uma variável-chave para explicá-lo. Fora da possibilidade de alternância de poder, típica de regimes democráticos, por mais que possuam garantias de independência e autoridade suficientes para decidir contra a vontade do regime em alguns casos pontuais, tribunais e juízes estariam muito limitados em sua atuação.

Entretanto, quando analisamos o papel do Supremo na derrota da Emenda das "Diretas Já", a variável da "democratização" pode, na verdade, explicar menos do que aparenta, ao menos no caso brasileiro, para compreender o processo de expansão do poder do Tribunal. Ainda durante o regime militar, o Supremo utilizou o poder de interpretação constitucional para resolver um conflito político de alta magnitude - uma questão que, embora apresentada sob uma roupagem técnica de processo legislativo, implicava, na prática, na definição do destino da transição para a democracia.

Na decisão, o STF se afastou do teor literal da constituição vigente e de sua própria jurisprudência anterior. Provocado por atores políticos a resolver um conflito fundamental sobre as próprias regras do jogo do processo de transição para democracia, o STF resolveu a questão clarificando/reformulando o sentido de normas constitucionais. Ao fazê-lo, criou novas regras gerais vinculantes para futuros conflitos políticos, reforçando sua própria autoridade como corte constitucional, mesmo em um ambiente não democrático, lançando as bases para o mesmo tipo de autoridade que viria a utilizar já após a transição democrática. Embora o presente artigo tenha uma pretensão apenas exploratória, a recuperação e discussão sistemática de outros casos semelhantes - casos de "judicialização antes da democratização" - pode contribuir para uma agenda mais ampla, que busque repensar, em termos mais precisos, a relação entre democracia e a expansão de poder judicial sobre a política.

Para uma crítica mais geral à ideia de que a experiência brasileira anterior a 1988 possa ser vista como "pré-história" constitucional, ver Lynch e Mendonça (2017).

Para uma revisão dos seus principais significados e usos na literatura, ver Hirschl (2010), para uma análise mais focada no debate brasileiro, ver Maciel e Koerner (2002). 


\section{Judicialização da política e democratização}

Em geral, as explicações para o fenômeno da crescente participação de tribunais de cúpula na política no Brasil e em outros países incluem os seguintes conjuntos de variáveis: (i) o uso que atores externos ao Tribunal, como o Congresso e o governo, fazem da Suprema Corte, provocando a sua jurisdição; (ii) as próprias preferências dos juízes, que seriam também protagonistas, em última instância, de uma transformação do grau de atuação política do Tribunal; (iii) variáveis de desenho institucional, ligadas às características do próprio texto constitucional (e de sua interpretação ao longo do tempo) que criam mecanismos para o judiciário possa ser provocado e venha a decidir esses conflitos. No caso do Brasil, essas características incluem tanto o desenho institucional dos poderes do Supremo Tribunal Federal no controle de constitucionalidade quanto, de maneira mais ampla, o tipo de ambição e de aposta que o texto contém em termos do papel do judiciário na efetivação de seus direitos e promessas. ${ }^{3}$

No primeiro sentido, alguns autores tentaram compreender esse fenômeno encarando o Congresso como um ator que provoca a jurisdição constitucional para que o STF decida questões que, em maior ou menor medida, surgem no âmbito do processo político. Em algumas perspectivas, o STF foi reconstruído como instrumento da minoria derrotada para tentar contornar decisões majoritárias (TAYLOR; DA ROS, 2008). Outros estudos, explorando casos que não o brasileiro, perceberam os tribunais constitucionais e cortes supremas como um instrumento de legitimação e fortalecimento da própria coalizão majoritária (WHITTINGTON, 2005), ou, ainda, enquanto parte da estratégia de partidos derrotados na arena política para ganhar atenção dos eleitores por meio da judicialização de suas demandas, ainda que com pouca ou nenhuma chance de vitória (DOTAN, 2005). Estratégias políticas de recurso ao Judiciário por razões independentes do eventual resultado favorável na decisão judicial também foram observadas no caso do Brasil (TAYLOR, 2008; TAYLOR; DAROS, 2008). Assim, além da utilidade do STF para o Congresso enquanto arena para reverter decisões majoritárias, o STF deveria ser pensado como instrumento de ampliação da atuação dos partidos frente à sociedade.

No segundo sentido, observa-se que, mesmo anos após a promulgação da Constituição Federal, e muito tempo após o STF ser provocado por atores políticos a utilizar os amplos poderes que havia recebido, havia uma variável geracional ainda limitando seu grau de participação na política nacional. Com a composição do Tribunal mantida intacta durante a transição para a democracia, ministros com concepções mais conservadoras da função judicial só deixaram o Supremo de maneira gradual. A maturação desse processo de mudança geracional, que só veio a se completar em meados dos anos 2000 , viabilizou níveis mais altos de participação do Tribunal, conforme interpretações restritivas foram sendo removidas de sua jurisprudência (ARGUELHES, 2014).

Por fim, há explicações que, deixando em segundo plano as estratégias dos que acionam o STF e as preferências dos próprios juízes, encontram no desenho constitucional e nas transformações políticas e institucionais do processo de democratização a principal chave explicativa para o aumento da atuação do Tribunal desde os anos 80 . Nesse sentido, por exemplo, sustentam que, com um maior escopo de matérias sob tutela da Constituição e, consequentemente, do Tribunal, além de um aumento dos atores aptos a provocarem-na, o STF teria sido levado a um aumento de seu espectro de ação (CARVALHO, 2007). Nessa explicação, pelo menos em sua primeira parte, a constitucionalização de uma gama maior de assuntos seria uma das expressões institucionais da redemocratização, que incluiria uma aposta constitucional em um judiciário ativo na efetivação de uma série de direitos sociais e outras promessas constitucionalizadas (BARROSO, 2010). Nessa perspectiva, a judicialização da política é resultado de compromissos, em termos de desenho institucional, que teriam sido positivados como parte do processo de redemocratização (VIANNA 1999). ${ }^{4}$

\footnotetext{
3 Para uma discussão mais ampla da interação entre essas variáveis na configuração do poder do STF de 1988 até hoje, cf. Arguelhes e Ribeiro (2016).

4 Essa última perspectiva não exclui de todo uma abordagem mais institucionalista, tendo em vista que uma Constituição ampla - tanto em termos da configuração do poder judicial que cria, como quanto às suas ambições substantivas mais amplas - é resultado de decisões tomadas por constituintes. No caso, portanto, a amplitude do controle de constitucionalidade pode ser em parte explicada em termos de uma decisão mais ambiciosa por parte dos constituintes - decisão essa que, por sua vez, pode também ser objeto de explicações políticas. Os trabalhos de Ginsburg (2003) e Jon Elster (1993, p.169-217) seguem por esse rumo. Vale ressaltar, porém, que, em qualquer perspectiva, "a vontade do Constituinte" coloca apenas o tabuleiro inicial, sem de fato tomar parte no jogo.
} 
De maneira mais geral, na discussão sobre o fenômeno da judicialização da política, tanto na literatura sobre o caso brasileiro quanto em outras experiências, é comum enxergar uma correlação positiva entre judicialização e democracia, ainda que diferentes estudos caracterizem essa influência e seus mecanismos de maneiras distintas (TATE, 1995; GINSBURG, 2003). ${ }^{5}$ Em qualquer hipótese, contudo, o estabelecimento de um regime democrático, mesmo combinado à existência de um poder inicial mínimo para tribunais declararem leis inconstitucionais, não é uma propriedade suficiente para a ocorrência de judicialização. $O$ fenômeno depende tanto de que os tribunais usem seus poderes de determinadas maneiras quanto de que os atores ao redor do Tribunal não apenas o provoquem, mas tenham um conjunto específico de atitudes diante das decisões judiciais.

Nesse sentido, Stone Sweet (1999) observa que o processo de judicialização da política passa necessariamente por: (i) a transformação de um conflito político "diádico" em um processo "triádico" de resolução de conflitos (no caso do controle de constitucionalidade, a tríade se forma com a convocação do Tribunal a resolver conflitos entre atores políticos); ${ }^{6}$ (ii) esse processo passa pela criação e justificação de novas estruturas normativas capazes de garantir uma legitimidade mínima do árbitro perante as partes em conflito. No caso de tribunais constitucionais, essa segunda propriedade significa que, ao contrário do que ocorre em instituições puramente arbitrais (i.e., instituições ad hoc que são formadas para resolver disputas específicas, sem qualquer pretensão de consistência entre decisões ao longo do tempo), as razões oferecidas são ao mesmo tempo uma aplicação e um detalhamento de regras gerais pré-existentes. ${ }^{7}$

A concepção de Stone Sweet (1999) não é a única possível, ou útil, para identificar e explicar o fenômeno da judicialização em um dado país, especialmente considerando a multiplicidade de sentidos e a carga normativa que a expressão assume em alguns estudos (MACIEL; KOERNER, 2002). Mas ela possibilita ressaltar características importantes para a compreensão do problema no Brasil. Mesmo em sistemas políticos já consolidados como democracias, não é inevitável que o papel do STF vá exibir as características do processo descrito por Stone Sweet (1999) em uma política "judicializada". Tudo depende de como as decisões do Tribunal serão percebidas pelos atores políticos - mais especificamente, o ciclo da judicialização é instalado e alimentado quando o Tribunal é bem-sucedido, perante as partes em conflito na política, em apresentar suas decisões como resultado de argumentos constitucionais que mantêm uma relativa autonomia em relação aos interesses da parte adversária no conflito. Mais do que convencer os políticos que a decisão é "técnica", o que importa é convencê-los de que a lógica da decisão não é idêntica à lógica do conflito político que extravasou a arena decisória majoritária.

Pode-se dizer, assim, que democratização não é considerada uma propriedade suficiente para ocorrência de judicialização. Mas ela seria uma propriedade necessária? A literatura parece indicar uma resposta negativa. Em uma obra coletiva pioneira ainda nos anos 90, Tate e Vallinder (1995) haviam observado que democracia é uma das importantes "condições facilitadoras" da judicialização da política - sem afirmar, contudo, um eventual caráter necessário dessa variável. Mais recentemente, uma série de trabalhos permite questionar a força dessa "condição facilitadora" ao explorar as funções que tribunais relativamente poderosos podem cumprir em regimes autoritários. De acordo com Moustafa (2007) e Moustafa e Ginsburg (2008), um nível mínimo de poder dos tribunais pode ser útil a um regime não democrático para (i) exercer controle sobre potenciais oponentes políticos, (ii) ajudar a legitimar o regime, (iii) dar enforcement às regras e procedimentos criados pelo regime, ampliando o controle central sobre a burocracia, (iv)

\footnotetext{
Essa correlação pode estar presente mesmo em teorias que não enxergam a judicialização como um fenômeno positivo para um uma democracia. No caso de Hirschl $(2004,2006)$, por exemplo, a democratização produz judicialização na medida em que o risco da alternância de poder (que imediatamente entra cena, em maior ou menor medida, em um regime democrático) faz com que certas elites promovam a transferência de poder para instituições judiciais como forma de preservar sua "hegemonia" - isto é, um conjunto de regras já existentes e que refletem ou promovem seus interesses ou valores morais e políticos -- em determinados campos da vida social.

$6 \quad$ Nas palavras de Stone Sweet (1999, p.150), "Each party must believe that it is better off attempting to resolve a dispute than dissolving the relationship altogether".

"In adjudicating, the dispute resolver simultaneously resolves a dyadic dispute and enacts elements of the normative structure. Both are forms of rule making [...] In justifying her decision-in telling us why, normatively, a given act should or should not be permitted-she [a instituição que resolve o conflito] makes rules of an abstract, general, and prospective nature. This is so to the extent that her decision clarifies or alters rules comprising the normative structure." (SWEET, 1999, p.156).
} 
encorajar investimentos por meio da promoção de segurança jurídica, e (v) assumir a responsabilidade pela implementação de políticas controvertidas, que poderiam de outra forma alimentar críticas ao regime.

O papel do Supremo Tribunal Federal na política nacional durante a ditadura militar brasileira já foi objeto de estudos específicos. O foco, porém, tende a ser as decisões do STF em casos concretos envolvendo dissidentes políticos do regime - decisões que, muitas vezes, tinham impacto político, e que ajudam a revelar as relações entre a função judicial e o regime militar de forma mais ampla. ${ }^{8}$ Neste trabalho, porém, trata-se do papel político do STF pela via do controle de constitucionalidade, pela qual acaba criando e reformulando, ao longo do tempo, regras constitucionais. Nessa perspectiva, para além da simples tolerância do regime, o que pode explicar um relativo aumento desse tipo do poder dos juízes em um sistema político autoritário? No caso aqui analisado, é possível verificar atuação política do STF antes da democratização, em uma decisão profundamente consequente para o regime (a Emenda das "Diretas Já"), dentro da perspectiva da literatura sobre as condições nas quais o poder judicial se expande ou se retrai.

Especificamente no caso Brasileiro, é comum encarar a promulgação da Constituição de 1988 como um marco decisivo para o processo de judicialização da política - e até mesmo uma condição necessária, ainda que insuficiente (ARANTES, 2015). ${ }^{9}$ Mas, quanto mais encontrarmos exemplos de judicialização de decisões políticas - talvez até mesmo de decisões "mega-políticas" ou de "política pura" (HIRSCHL, 2006), conflitos de alta intensidade que afetam de forma profunda aquela sociedade - antes da nova constituição, mais poderemos colocar em questão se a expansão do poder do Supremo foi, de fato, um fenômeno umbilicalmente ligado à redemocratização. Como veremos, o caso das "Diretas Já" no Supremo permite ao menos levantar a hipótese de que as raízes do papel político atual do Supremo Tribunal Federal poderiam ser encontradas em condições presentes antes da própria Constituição de 1988.

Enfrentar essas perguntas exigiria análise aprofundada das condições institucionais e das estratégias políticas que o Tribunal pôde exercer, em um caso tão relevante quanto o das "Diretas Já", o poder de controle de constitucionalidade. Aqui, porém, nosso objetivo é mais preliminar. Tentaremos estabelecer que a decisão das "Diretas Já" é um caso de judicialização da política dentro do marco teórico proposto por Stone Sweet (1999). Procuraremos estabelecer se, para além do fato da provocação para decidir um conflito político, o Tribunal atuou de maneira a criar e justificar novas estruturas normativas no nível constitucional - estruturas que conseguiram comandar a obediência dos atores envolvidos, e que não foram diretamente apresentadas, nem percebidas como um simples prolongamento do poder das partes em conflito.

\section{A Emenda Dante de Oliveira}

Em abril de 1983, um jovem deputado do MDB de Mato Grosso apresentou no Congresso um projeto de emenda contendo sua maior promessa de campanha: o retorno das eleições diretas para o cargo de presidente. Batizada com o nome de seu autor, a Emenda Dante de Oliveira ganhou rápida adesão dentro do partido, e parlamentares como Freitas Nobre e Ulysses Guimarães negociaram com Luiz Inácio Lula da Silva uma adesão conjunta à proposta. As eleições de 1982 haviam sido ruins para os militares e, no ano em que se completava 20 anos de deposição de João Goulart e da instauração do regime militar, a PEC se tornou o símbolo e a soma das esperanças de mudar o regime.

Deu-se início ao movimento que ficou conhecido como "Diretas Já", que se iniciou ainda em junho 83, no Ginásio Popular, em Goiânia, local onde oito mil pessoas ouviram o discurso de Ulysses Guimarães;

\footnotetext{
Pereira (2005; 2008) e Osiel (1995), por exemplo, comparam o caso brasileiro com Argentina e Chile para explicar variações no papel dos juízes em geral, em cada país, em termos de maior resistência ao regime (Osiel) ou de mais cooperação entre o judiciário e o regime (Pereira), no caso do Brasil. Pereira (2005; 2008), por exemplo, fornece elementos importantes para explicar porque o regime não interveio na independência e nos poderes do judiciário no Brasil com a mesma intensidade ocorrida na Argentina e no Chile. A chave de sua explicação é, de forma sintética, a atitude do regime com relação às instituições judiciais e ao direito em geral. Essa relativa tolerância teria ocorrido porque, no Brasil, intervir no judiciário de forma mais intensa não era necessário, considerando a intensidade (baixa) da oposição armada ao regime e o grau de integração entre elites políticas e judiciais antes do próprio estabelecimento do regime.

9 Para uma revisão da literatura sobre o poder de tribunais na América Latina, discutindo a insuficiência do desenho original, ver também e Arguelhes e Süssekind (2018).
} 
depois, em agosto do mesmo ano, dez mil pessoas compareceram ao Comício do Pacaembu. No fim desse mesmo ano, General Figueiredo transmitiria uma mensagem em que dizia que a campanha "tinha caráter meramente perturbador" (BERTONCELO, 2007, p.126). Em março de 84, acrescentou: "se eleições diretas fossem solução, não haveria crise nos países que têm eleição direta”. ${ }^{10}$ (BERTONCELO, 2007, p.126). Essas reações não impediram que, em abril de 1984, ocorressem os famosos comícios na Cinelândia, em Brasília, com a presença de um milhão de pessoas, e no Anhangabaú, com presença de Ulysses Guimarães, Tancredo Neves, Lula da Silva, Leonel Brizola, Fernando Henrique Cardoso e 1,7 milhão de pessoas.

A campanha consistiu em um movimento suprapartidário envolvendo os principais partidos de oposição ao regime militar em torno da bandeira das eleições diretas. Foi o maior movimento cívico/popular da história brasileira. Partidos como PMDB, PT e PDT agiam como "Comitê Nacional Partidário Pró-Diretas", ${ }^{11}$ enquanto PCB e PCdoB contribuíam difundindo o movimento, assim como UNE, CNBB, OAB e outras (RODRIGUES, 2003). Apesar de algumas divergências localizadas entre os partidos sobre se o movimento deveria negociar com o regime a condução dos protestos (RODRIGUES, 2003), o movimento ocorreu de forma unificada. O PT, liderado por Lula e embalado desde 78 pelas greves no ABC, argumentava contra qualquer tipo de diálogo ou negociação com os militares, enquanto o MDB não só escolheu o caminho do diálogo para a condução segura das manifestações, como também interveio diretamente junto a militares e à esquerda para que tudo corresse na mais perfeita ordem (DELGADO, 2007). ${ }^{12}$

Apesar da magnitude do movimento, o apoio à Emenda Dante de Oliveira dentro do Congresso não teve o mesmo quórum da mobilização política das ruas, alcançando somente 298 dos 320 votos necessários na Câmara dos Deputados. A derrota poderia ter sido evitada se, ao menos, parte dos 113 deputados ausentes tivessem votado a favor da emenda. Desses 113, 112 eram do PDS, partido de José Sarney, envolvido em uma tentativa de esvaziamento da votação. ${ }^{13}$ Mais ainda: houve uma tentativa, por parte dos militares, de prejudicar a votação naquele dia 25 de abril. Medidas de emergência foram estabelecidas pelo General Newton Cruz no Distrito Federal e em municípios vizinhos desde as vésperas da votação, com a proibição de manifestações e censuras à imprensa. ${ }^{14} \mathrm{Em} 26$ de abril de 1984, a Folha de São Paulo ${ }^{15}$ publicava: "Use preto pelo Congresso Nacional", "A Nação Frustrada!" e "Apesar da maioria de 298 votos, faltaram 22 para aprovar diretas". A heterogênea aliança forjada no seio do movimento se dissipou já no dia 26, deixando em seu lugar a disputa pela herança simbólica do movimento entre os diferentes partidos que estiveram na luta.

Contudo, para parte dos deputados e ativistas políticos pró-diretas, porém, não havia ali uma derrota. Ao contrário: legalmente, constitucionalmente, o quórum necessário havia sido obtido na votação. Segundo a Constituição de 1967, para ser apresentada, uma proposta de emenda à constituição "deverá ter a assinatura de um terço dos membros da Câmara dos Deputados ou do Senado Federal"; e seria aprovada quando conseguisse obter, "em ambas as votações, dois terços dos votos dos membros de suas Casas." Para esses parlamentares, a diferença na redação ("dos membros" e "dos votos dos membros") era decisiva, e não poderia levar a uma única interpretação para os dois dispositivos. Para alguns defensores da Emenda Dante de Oliveira, o dispositivo relativo à aprovação exigia, literalmente, dois terços dos presentes, e não de todos os representantes da casa. Se essa interpretação fosse de fato adotada, considerando-se o número de presentes no dia da votação, bastaria o quórum de 242, e não 320 votos, para o restabelecimento das eleições diretas no Brasil.

10 Jornal Folha de São Paulo, 16 de março de 1984, p.4, Disponível em: <http://acervo.folha.uol.com.br/resultados/?q= \%E2\%80\%9Cse+elei\%C3 $\%$ A7\%C3\%B5es+diretas+fossem+solu $\%$ C3\%A7\%C3\%A3o\%2C+n\%C3\%A3o+haveria+crise+nos+pa $\%$ C3\%ADses+que+t $\%$ C3 $\% A A m+$ elei $\%$ C3 $\% \mathrm{~A} 7 \% \mathrm{C} 3 \% \mathrm{~A} 30+$ direta $\% \mathrm{E} 2 \% 80 \% 9 \mathrm{D} \&$ site=\&periodo=acervo\& $\mathrm{x}=10 \& \mathrm{y}=13>$.

11 Formando inclusive a caravana das diretas, percorrendo várias cidades da região norte e nordeste durante janeiro e fevereiro de 1984 (BERTONCELO, 2009, p.178).

12 Tancredo Neves, enquanto governador, teria não só presidido a comissão que organizou os protestos em Belo Horizonte, como viria a se responsabilizar pela ordem pública e pelo tom dos discursos, pedindo ao Comandante da Divisão do Exército que na colocasse a tropa de prontidão e solicitando aos comunistas que não ostentassem o símbolo da foice e do martelo (DELGADO, 2007).

13 Ver depoimento do Deputado Paulo Maluf em:<http://www.camara.gov.br/internet/agencia/infograficos-html5/diretas/index.html>

14 Quanto a esse episódio, Ulysses discursaria na Câmara: "Sem a mordaça da censura, sem o General Newton Cruz tirar, abusivamente, os interlocutores dos ônibus e automóveis das cercanias de Brasília, ameaçados por baionetas, metralhadoras, camburões, cães amestrados e pregos nas estradas. "Episódio retratado nos jornais no dia seguinte à votação, ver Jornal Folha de São Paulo, 26 abr. 1984 , p. 17. Disponível em: <http://acervo.folha.uol.com.br/fsp/1984/04/26/2/\#>.

15 ver Jornal Folha de São Paulo, 26 abr. 1984, p.1. Disponível em: <http://acervo.folha.uol.com.br/fsp/1984/04/26/2/\#> 
Essa posição levantava, em seu favor, uma série de argumentos e questões constitucionais, que não poderiam ser facilmente reduzidos a uma simples expressão de descontentamento com uma derrota na política majoritária. Ao contrário, os argumentos levantados apelavam para as próprias regras do jogo para afirmar que, na verdade, a maioria havia prevalecido na votação, mas uma minoria havia negado, injustamente, a sua vitória. Faria sentido que houvesse uma redação diferente dos critérios para a propositura (dos membros) e aprovação (dos votos dos membros) da emenda, se queriam dizer a mesma coisa? Como haviam sido interpretadas as Constituições anteriores a 67, e que possuíam redação análoga nos dispositivos correspondentes? Qual era a tradição brasileira quanto a esse ponto - tanto na formulação de regimentos legislativos e constituições anteriores quanto na jurisprudência do Supremo Tribunal Federal? Para além de um cálculo político, o sucesso da Emenda Dante de Oliveira - e do caminho até ali escolhido para a redemocratização - parecia depender, naquele momento, de uma disputa sobre interpretação constitucional, como veremos a seguir.

\section{0 parecer de José Paulo Cavalcanti e a controvérsia sobre a atuação do STF}

No dia seguinte à votação no Congresso, o advogado pernambucano José Paulo Cavalcanti publicou artigo em jornal do Recife questionando o quórum e, consequentemente, o resultado obtido. Após isso, os congressistas Severo Gomes, Ayrton Sandoval e o então Governador de São Paulo, Orestes Quércia, impetraram o Mandado de Segurança $n^{\circ} 20.452$ com argumentação no mesmo sentido. Com o fracasso do MS, indeferido por unanimidade no STF, José Paulo Cavalcanti (2015) (custeia publicação na Folha de São Paulo em 11 de novembro sob o título "O Supremo e as Diretas", na qual analisava não só a votação do Congresso, como já havia feito, mas também a decisão proferida pelo Supremo alguns dias antes. ${ }^{16}$

O argumento sustentava que a Emenda Dante de Oliveira havia, na verdade, sido aprovada, já que quando a Constituição de 67 dizia "dois terços dos votos dos membros de cada uma das casas", queria dizer algo bem diferente de "voto de dois terços dos membros". Assim, o quórum dizia respeito a dois terços dos presentes, e não do total de membros da casa. Ao argumentar nesse sentido, o advogado se referia à seguinte redação:

Art. 47. A Constituição poderá ser emendada mediante proposta:

I - De membros da Câmara dos Deputados ou do Senado Federal; ou

II - Do Presidente da República.

$\S 1^{\circ}$ Não será objeto de deliberação a proposta de emenda tendente a abolir a Federação ou a República.

$\S 2^{\circ} \mathrm{A}$ Constituição não poderá ser emendada na vigência de estado de sítio.

$\S 3^{\circ}$ No caso do item I, a proposta deverá ter a assinatura de um terço dos membros da Câmara dos Deputados ou do Senado Federal.

Art. 48. Em qualquer dos casos do artigo anterior, itens I e II, a proposta será discutida e votada em reunião do Congresso Nacional, em duas sessões, dentro de sessenta dias, a contar da sua apresentação ou recebimento, e havida por aprovada quando obtiver, em ambas as votações, dois terços dos votos dos membros de suas Casas. (Grifo nosso)

Segundo Cavalcanti (2015), diferente da primeira sentença, a qual trata do número de assinaturas para apresentação da proposta, no momento da aprovação, quando a constituição fala de "voto", estaria se referindo a algo já manifestado. Portanto, não poderia se referir a um ausente, mas tão somente àqueles que, presentes, votaram contra ou a favor. Assim, seriam necessários 242 e não 320 votos para aprovação da emenda.

No dia seguinte à publicação, o "Jornal do Brasil", na seção "Informe JB" publicou nota dizendo que Paulo Cavalcanti não teria advogado no caso porque não teriam substabelecido uma procuração. Paulo Cavalcanti pediu que jornal esclarecesse que o parecer não Ihe havia sido pedido por ninguém, e que ele mesmo teria custeado sua viagem para Brasília para assistir o julgamento. 
Em um primeiro momento, a publicação do parecer não parece surtir qualquer efeito. A questão fica esquecida até 88 , quando Cavalcanti (2015) retorna ao tema para se defender da acusação de que teria feito parecer a pedido dos impetrantes. Ele escreve novo texto em que não só reafirma os argumentos dos pareceres, como rebate ponto a ponto a argumentação feita pelos Ministros no julgamento do MS. De forma bastante direta, Cavalcanti conclui acusando o STF de ter, por meio da interpretação, emendado a Constituição, sem que tenha havido, no caso, qualquer motivo de interesse público aparente para essa atitude.

\title{
4.1 A jurisprudência do Supremo: o Acórdão de 1926
}

Nesta seção, vamos analisar em detalhes a argumentação de Cavalcanti. Procuraremos mostrar que ela é bastante sólida do ponto de vista jurídico - suficientemente sólida para podermos dizer que, legalmente, o Supremo tomou uma decisão criativa, respondendo a um conflito político com a formulação de regras constitucionais novas. Ainda que essa formulação tenha sido apresentada como mera "interpretação" ou "aplicação" da Constituição, ela constitui um tipo de rulemaking que é necessário para a ocorrência de judicialização da política. Se os argumentos de Cavalcanti forem de fato sólidos, o caso da Emenda Dante de Oliveira nos permite olhar para o processo de expansão de poder político do STF sob uma perspectiva inexplorada. Afinal, tratava-se, ali, de um regime não democrático, e o acesso ao Supremo era limitado. Além disso, foi provocado a se manifestar sobre uma questão política fundamental para a própria natureza do regime político - e, assim como ocorre nas decisões judicializadas nos dias de hoje, tomou sua decisão com argumentos constitucionais que alteraram as próprias regras do jogo político de forma substantiva.

A crítica de Cavalcanti ao Supremo depende, em larga medida, de um acórdão do próprio STF, datado de 1926 - do qual o autor do parecer afirma ter tomado conhecimento apenas na véspera do julgamento. ${ }^{17}$ Naquele caso, decidido questão idêntica, mas com relação à Constituição de 1891, julgando constitucional emenda aprovada por $2 / 3$ dos votos, mas não dos membros.

\begin{abstract}
Dizia a Constituição de 1891:
Art. 90 - A Constituição poderá ser reformada, por iniciativa do Congresso Nacional ou das Assembléias dos Estados.

$\S 1^{\circ}$ - Considerar-se-á proposta a reforma, quando, sendo apresentada por uma quarta parte, pelo menos, dos membros de qualquer das Câmaras do Congresso Nacional, for aceita em três discussões, por dois terços dos votos em uma e em outra Câmara, ou quando for solicitada por dois terços dos Estados, no decurso de um ano, representado cada Estado pela maioria de votos de sua Assembléia.

$\S 2^{\circ}$ - Essa proposta dar-se-á por aprovada, se no ano seguinte o for, mediante três discussões, por maioria de dois terços dos votos nas duas Câmaras do Congresso.

$\S 3^{\circ}$ - A proposta aprovada publicar-se-á com as assinaturas dos Presidentes e Secretários das duas Câmaras, incorporar-se-á à Constituição, como parte integrante dela.

$\S 4^{\circ}$ - Não poderão ser admitidos como objeto de deliberação, no Congresso, projetos tendentes a abolir a forma republicano-federativa, ou a igualdade da representação dos Estados no Senado.
\end{abstract}

O STF foi chamado a interpretar as expressões acima destacadas no Habeas Corpus 18.178, interposto em um cenário político conturbado. Após vivenciar uma série de revoltas populares nas zonas rural e urbana - como Canudos (1895-1897), Vacina (1904), Chibata (1910) e Contestado (1912-1916) -, o país assistia a um fortalecimento dos movimentos sindicais e de correntes ideológicas socialistas, comunistas e anarquistas, catalisados pela imigração europeia e a urbanização latente no período após a $1^{\text {a }}$ Guerra Mundial. Além das greves e revoltas dos trabalhadores, fortalece-se a defesa de um liberalismo autêntico por parte de uma classe média urbana. Em meio a esse arranjo fértil, surgem revoltas militares de caráter ideológico difuso, inspiradas no movimento tenentista, como a Revolta do Forte Copacabana

17 As mudanças feitas pela Emenda de 3 de setembro de 1926 à Constituição de 1891 podem ser verificadas na versão disponível em: <http://www. planalto.gov.br/ccivil_03/constituicao/Constituicao91.htm>. 
(1922), a Revolução Constitucionalista (1924), ocorrida na cidade de São Paulo, e, posteriormente, da Coluna Prestes (1925-1927), cujos membros eram os pacientes do HC de 1926.

A conjuntura resultava em um ambiente de hostilidade generalizada por parte não só de movimentos operários - que se organizavam em sindicatos -, como de tenentes e coronéis insatisfeitos, que viam Arthur Bernardes, do Partido Republicano Mineiro (1922-1926), e seu sucessor, Washington Luís do Partido Republicano Paulista (1926-1920), como servidores de interesses oligárquicos. Bernardes governou por quase todo o seu mandato em estado de sítio. Durante os meses que precediam a passagem de poder, o cenário se torna agudo, com o crescimento do Partido Democrático formado por dissidentes dos partidos republicanos e outros descontentes do cenário industrial e agrário, além de profissionais liberais.

Em setembro de 1926, o temor do Partido Republicano resulta em uma reforma constitucional da Constituição de 1891, tendo por objetivo o aumento dos poderes do executivo. Tal reforma previa, em seu Art. $60, \S 5^{\circ}$, que

nenhum recurso judiciário é permitido, para a Justiça federal ou local, contra a intervenção nos estados, a declaração do estado de sítio, e a verificação de poderes [...] assim como, na vigência do estado de sítio, não poderão os tribunais conhecer dos atos praticados em virtude dele pelo Poder Legislativo ou Executivo.

O parágrafo permitia que se deixassem fora do âmbito do controle judicial os atos praticados pelos Poderes Executivo e Legislativo durante o estado de sítio - o que significava impedir a concessão de habeas corpus nos casos de prisões realizadas quando da decretação daquela medida de exceção (JUNQUEIRA, 2001).

A interpretação do alcance dessas reformas é feita pelo Supremo em uma série de habeas corpus interpostos por membros de movimentos oprimidos pelo executivo. Um dos motivos da reforma constitucional promovida pelo Executivo, porém, consistia justamente em limitar o alcance dos HC apreciados pelo Supremo no decorrer desses anos de conjuntura delicada (ROLDAN, 2014). Sete dias após a promulgação da reforma, ${ }^{18}$ o HC é interposto em favor de mais de 150 soldados que estavam presos e incomunicáveis na llha de Trindade, a 800 milhas da costa brasileira, em virtude de sua participação na Coluna Prestes.

O pedido era no sentido de mantê-los em prisões comuns em terra. No entanto, os advogados levantam uma preliminar quanto à constitucionalidade da reforma que havia permitido aquelas prisões. Argumentavam haver um vício de procedimento, já que a mesma não teria sido aprovada por dois terços do Senado. Nas duas principais emendas da reforma questionada, 38 e 35 senadores teriam votado a favor, quando dois terço dos 63 senadores que integravam a casa à época seriam 42 senadores.

A tese adotada pelo HC é semelhante à que o Supremo viria a adotar no caso das Diretas Já, e os advogados discutem e procuram afastar a tese de que o quórum de dois terços não tem por base todos

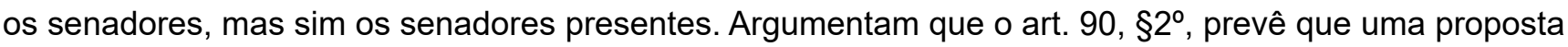
de emenda seria aprovada "por maioria de dois terços dos votos nas duas Câmaras do Congresso". Para os autores, ao adotar essa formulação, os constituintes indicam que, conversamente, teriam adotado uma formulação oposta (e inequívoca) se desejassem que a contagem dos votos envolvesse somente os votos dos presentes. Defendem, portanto, que o legislador haveria de exigir mais, e não menos rigor, na votação de emendas. ${ }^{19}$

No entanto, o STF não aceita a tese da inconstitucionalidade da reforma constitucional. Os ministros afirmam que a constituição de 1891 deixa claro em vários de seus artigos que o voto se dará sobre o total dos presentes, adotando, para tanto, uma redação expressa. É o caso, por exemplo, do Art. 33, §2 ("[O

\footnotetext{
Enquanto a reforma entra em vigor em 4 de setembro de 1926, o HC é interposto em 11 de setembro do mesmo ano.

Para sustentar essa leitura do texto de 1891, o HC utiliza argumentos doutrinários e de história legislativa. Cita, por exemplo, parecer da "Comissão dos 21", que havia sugerido que a aprovação dependente do voto dos dois terços já seria uma flexibilização de uma regra de maioria mais rígida do que a sugerida anteriormente, ou seja, três quartos - uma posição que, segundo os autores, só faria sentido a Comissão tivesse adotado a mesma a interpretação que pedem ao STF que adote. Mencionam, ainda, a opinião do jurista João Barbalho, que equivaleria a uma espécie de "interpretação autêntica" tendo em vista que se tratava de um constituinte de 1891.
} 
Senado] Não proferirá sentença condenatória senão por dois terços dos membros presentes); Art. $37,3^{\circ}$ ("Devolvido o projeto [de lei] à Câmara iniciadora, ai se sujeitará a uma discussão e à votação nominal, considerando-se aprovado, se obtiver dois terços dos sufrágios presentes. [...]"); e Art. 39, §1 ("No caso contrário, [o projeto de lei] volverá à Câmara revisora e, se as alterações obtiverem dois terços dos votos dos membros presentes [...)").

Em contraste, no artigo $90, \S 2^{\circ}$, ao tratar do quórum para reforma da constituição, a redação é claramente distinta. Não se fala em votos "dos presentes", mas simplesmente de "dois terços dos votos [nas duas Câmaras do Congresso]". Nesse sentido, o acórdão de 1926 conclui que "na tramitação parlamentar da Reforma Constitucional não foi violada cláusula alguma da Constituição da República. O quórum de aprovação das emendas à Constituição é de dois terços dos votos dos congressistas presentes". ${ }^{20}$

Recuperando o texto do acórdão para atacar a posição do Supremo dos anos 80 sobre a mesma questão, Cavalcanti (2015) cita diversos trechos dos votos de ministros, como os de Aurelino Leal e Carlos Maximiliano, que confirmam a visão do Tribunal. ${ }^{21}$ Em voto no mesmo acórdão de 1926, o ministro Heitor de Souza explicita que:

Em todas as leis, constitucionais ou ordinárias, em todos os regulamentos ou regimentos - de corporação legislativa, de tribunais administrativos ou judiciários e de assembleias ou associações de qualquer natureza, o vocábulo votos tem a significação invariável de manifestação e expressão da vontade do titular da função colegial respectiva, presente à deliberação. Não se pode usar desse vocábulo em se tratando de assembleias legislativas, em que a representação é essencialmente pessoal e não pode ser exercida por procuratura, sem desde logo designar-Ihe aquele significado. Daí decorre como consectário lógico e inevitável que a locução 'dois terços de votos' é equivalente a esta outra 'dois terços dos presentes'.

Posição semelhante é encontrada nos votos dos ministros Bento de Faria ("Por - voto - se entende o ato que só em assembléia pode ser praticado pelos presentes a ela"), Arthur Ribeiro ("Os votos dados na sessão são, como é evidente, os votos dos que se acham presentes, porque os ausentes não votam, e é presunção jurídica, em matéria de direito parlamentar, que os presentes representam os ausentes") e Pedro dos Santos ("Entretanto, sempre se tem entendido que - dois terços de votos - ou a maioria absoluta de votos, são expressões que designam o quórum calculado entre os presentes"). Os votos fornecem, ainda, diversos argumentos doutrinários de autoridade que não parecem ter envelhecido com o tempo. Do voto do Ministro Godofredo Cunha, por exemplo, ele recupera uma referência a Rui Barbosa - que, ao se deparar com o projeto de Constituição apresentado pela "comissão dos cinco", ${ }^{22}$ teria achado excessivo que fosse necessário $2 / 3$ da totalidade para se reformar a Constituição, e que $2 / 3$ dos votos bastariam. ${ }^{23}$

Na prática e no pensamento constitucional brasileiro, há poucos critérios minimamente consensuais para definirmos quando estamos, de fato, diante de um "precedente" passado aplicável a um caso presente. ${ }^{24}$ Contudo, a argumentação de Cavalcanti parece desenhar um cenário bastante difícil para quem pretenda

20 Além disso, no acórdão de 1926, a discussão incorporou decisões da Suprema Corte e da Constituição dos EUA, onde, segundo os ministros, não haveria dúvida de que a maioria de $2 / 3$ se calculava sobre o número de presentes e não sobre o número total dos congressistas. Como veremos a seguir, Cavalcanti também invoca a autoridade da jurisprudência e da doutrina dos EUA para defender sua leitura da constituição em 1984.

21 Por exemplo, o voto do Ministro Godofredo Cunha, citando João Mangabeira:

"Não pode haver, seriamente, dúvida a tal respeito, uma vez que se atente nos termos do artigo 90 , que estabelece três fases para a reforma: a da proposta que deve ser "apresentada por uma quarta parte, pelo menos, dos membros de qualquer das Câmaras"; $2^{\circ}$ a da aceitação "por dois terços dos votos em uma e outra câmara"; $3^{\circ}$ a da aprovação também "por dois terços dos votos nas duas Câmaras". Em resumo, a constituição estabeleceu duas situações diferentes. Exigiu para a apresentação uma quarta parte dos membros ou 53 deputados ou 16 senadores. Para a aceitação e aprovação não reclamou, porém, dois terços dos membros, e sim "dois terços dos votos", que é coisa muito diversa." (CAVALCANTI, 2015).

22 "O Decreto $n^{\circ} 29$, de 3 de dezembro de 1889, nomeou a comissão incumbida de preparar o projeto a ser apresentado ao Congresso Nacional Constituinte. A comissão, que se tornaria conhecida como Comissão de Petrópolis, ou Comissão dos Cinco, era composta por Joaquim Saldanha Marinho - que viria a presidi-la -, Américo Brasiliense de Almeida Melo, Antônio Luís dos Santos Werneck, Francisco Rangel Pestana e José Antônio Pedreira de Magalhães Castro." In Verbetes CPDOC, Primeira República, Assembleia Constituinte de 1891.

23 Menciona também a posição de doutrinadores como Francisco Campos, que, à época, acreditavam que a Constituição requeria dois terços dos presentes e não dos votos.

24 Para análise de dois recentes julgamento que ilustram de forma detalhada esse problema, ver Fernando Leal (2016, 2017). Para uma discussão mais geral da problemática relação do Supremo com a criação de precedentes para o futuro, ver Vojvodic et al. (2009). 
ignorar a decisão de 1926 e o que ela aponta quanto à interpretação do quórum constitucional nesse tipo de caso.

\title{
4.2. O Supremo atuou como legislador constitucional?
}

Para Cavalcanti, seria difícil imaginar que esse acórdão de 1926 tenha passado despercebido aos ministros da Corte no julgamento das "diretas", considerando, talvez, que a existência de um alegado precedente tão claro deveria ser suficiente para encerrar a disputa. ${ }^{25} \mathrm{E}$ certo que, em disputas interpretativas, não existem fatos incontroversos, mas, ainda assim, é possível afirmar que os argumentos de Cavalcanti (1998) desenham, de forma bastante persuasiva, um cenário no qual (i) tanto o texto quanto a tradição do direito constitucional parecia apontar no sentido da aprovação da Emenda das Diretas Já e (ii) essa tradição interpretativa deveria ser do conhecimento dos ministros do Supremo. Entretanto, como vimos, o acórdão do STF de 1984 vai na direção oposta, colocando textualmente o contrário:

\begin{abstract}
Aliás, é da tradição do nosso Direito Constitucional ser o quórum adotado para a aprovação de emenda constitucional tomado sempre levando-se em conta o total de Deputados e Senadores, em conjunto ou separadamente, por maioria ou por dois terços, mas sempre com referência ao total existente, e não dos presentes. (CAVALCANTI, 2015, p. 388).
\end{abstract}

Examinando os votos daquele julgamento, Cavalcanti acusa os ministros de compreenderem a Constituição de 1967 não como ela era, mas como pensam que deveria ser. Em seu voto, o ministro Aldir Passarinho afirma que, caso a emenda tivesse sido aprovada, haveria um paradoxo, pois a aprovação de uma emenda careceria de número de votos inferior àquele de apresentação da proposta. Rebatendo esse ponto, Cavalcanti argumenta, primeiramente, que não haveria como o número para a apresentação da emenda ser baseado no número de votos, tendo em vista que os votos só podem ser proferidos depois da apresentação. E o fato de a apresentação da proposta ser baseada no número de membros (não havendo outra opção) não vincula que o mesmo critério, e não o de votos, seja usado na aprovação da emenda. Além disso, o número de votantes ser menor do que o número necessário para a apresentação da proposta seria uma exceção.

O argumento do ministro Passarinho faz ainda menos sentido, argumenta Cavalcanti $(2015$, p. 383384 ) tendo em vista que quando o STF, no julgamento de 1926, entendeu que a aprovação se dava com base no número de votos, e a Constituição de 1891 exigia ainda menos para a apresentação de emenda do que a Constituição de 1967, "uma quarta parte, pelo menos, dos membros de qualquer das Câmaras do Congresso Nacional".

Nos votos dos ministros Bento de Faria e Arthur Ribeiro, aliás, a conclusão foi justamente a contrária, já que, para apresentação, a Constituição exigia "uma quarta parte, pelo menos, dos membros" e "dois terços dos votos" para aprovação. Trata-se de conclusão diferente da de Passarinho ao interpretar o parágrafo a Constituição de 1967. O mesmo entendimento é confirmado por outro enxerto de João Mangabeira colocado por Cavalcanti, em que o autor defende que, se não há voto no Congresso por procuração, então $2 / 3$ dos votos tem que ser $2 / 3$ dos presentes.

Para além desses esquecimentos doutrinários, Cavalcanti (2015, p. 391) ataca diretamente o que percebe como a ignorância do ministro sobre o texto e a jurisprudência constitucionais:

E aquela desatenção dos autores invocados pelo Ministro Aldir Passarinho é também evidenciada pelo fato de que todos eles referem o art. 48 da Constituição de 1967 como se exigisse o voto de dois terços dos membros, quando peremptoriamente exige dois terços dos votos; sem absolutamente nada nenhum deles dizer para explicar a alteração que, assim introduziram na regra constitucional, alteração de que, como se conclui do seu silêncio, nem sequer advertem.

\footnotetext{
25 Vale registrar artigo de Sepúlveda Pertence (2007), no qual, ao tratar do controle de constitucionalidade de emendas, fala da controvérsia ocorrida em 1926 em torno do quórum como se fosse uma questão amplamente conhecida dentro do repertório jurisprudencial da instituição.
} 
O erro cometido por Passarinho é apontado também no voto do ministro Francisco Rezek, o qual afirma que "membros" diz respeito à totalidade dos membros da casa. No entanto Cavalcanti argumenta que o texto desse dispositivo continua com a expressão "dos votos dos membros" - o que seria algo totalmente diferente, já que, novamente, só poderia emitir voto quem estivesse presente. No mesmo sentido está o posicionamento do ministro Oscar Correa, para quem "a tradição imemorial do Congresso, em matéria de votação de Emendas Constitucionais [...] sempre foi de 2/3 ou maioria absoluta dos membros de cada uma das casas do Congresso Nacional". Trata-se, porém, de uma afirmação que pode ser facilmente questionada a partir do julgamento de 1926. Para Oscar Correa, condicionar ao quórum de votação seria apregoar "o reinado do descritério; que coloca a modificação substancial da própria Constituição na dependência de um dado variável, incerto, e subordinado a inexpressiva votação, menos expressiva do que a do veto governamental e da votação de leis complementares e equivalente à das leis ordinárias".

Cavalcanti (2015) responde que o argumento importaria a radical proscrição do critério de apuração das maiorias pelo número de votos, que tem em conta os que comparecem e votam, e não os que se omitem, não comparecendo, ou comparecendo e não votando.

Além disso, no acórdão de 1926, o ministro Hermenegildo de Barros afirma que o legislador teria optado pelo critério dos votos justamente por achar que, pela importância da questão, os congressistas cumpririam o dever de não faltar às sessões, sendo bastante $2 / 3$ dos presentes. Dos ausentes não se deve presumir qualquer posicionamento, mas tão somente a indiferença. Segundo o ministro Godofredo Cunha, "[...] não é razoável que os que intervêm com diligência nas sessões sejam condenados à inação pela indolência dos outros." (CAVALCANTI, 2015, p. 394).

Cavalcanti argumenta que, das funções públicas, não decorrem para o sujeito ativo direitos, cujo exercício é livre. Decorrem poderes-deveres, cujo exercício, verificada a correspondente situação de fato, é imperativo; em consequência, quando o sujeito ativo se omite, faltando a esse fundamental dever de exercício, não pode ter o contraditório poder de, com o descumprimento de um dever de exercício, causar a ineficácia do seu cumprimento por outros sujeitos ativos. No poder público, o critério da maioria dos votos é o único coerente.

Também não parecem críveis, para Cavalcanti, as preocupações dos ministros quanto à rigidez da constituição, como se esta pudesse ser, de fato, ameaçada pela interpretação de que a emenda é aprovada pelo voto dos presentes. Trata-se mais de uma preocupação pragmática do que de um argumento sobre o significado da expressão contida no texto constitucional. Para Cavalcanti, a experiência demonstra que, qualquer que tenha sido o seu desenho, com maior ou menor rigidez, as constituições não duram indefinidamente. Elas são alteradas, inclusive, por meio de decisões judiciais, e Cavalcanti afirma que o próprio acórdão proferido pelo Supremo em 7 de novembro de 1984 seria uma indireta emenda da Constituição de 1967, feita por meio de interpretação judicial, e com uma grande virada na jurisprudência do STF.

O ministro Moreira Alves afirma em seu voto: "ninguém tem dúvida de que a Constituição brasileira, desde a implantação da república, é rígida, o que implica dizer que a votação de emenda constitucional exige quórum qualificado". Segundo o autor, esse trecho contém alguns problemas. Primeiro, Moreira Alves usa a palavra quórum em vez de maioria. Quórum seria o número de representantes necessários ao funcionamento de uma câmara legislativa, enquanto maioria diz respeito aos votos proferidos. Nesse sentido, "maioria absoluta", ao contrário do que acredita Moreira Alves, não seria mais da metade dos membros do colégio, mas tão somente mais da metade do que o coletivo sobre o qual se calcula, podendo ser esse número o da totalidade dos membros, dos presentes, dos votantes, etc. Segundo, a "maioria qualificada", que Moreira Alves chama de quórum, não é a única maneira de tornar uma constituição rígida ou mais rígida; há outras formas, como a repetição da votação em sessões diversas.

Com relação à distinção entre quórum e maioria, Cavalcanti $(2015$, p. 379) exemplifica com a Lei das Sociedades Anônimas, vigente à época: "as deliberações da assembleia geral [...] serão tomadas por maioria absoluta de votos não se computando os votos em branco" Então, ao contrário do que diz Moreira Alves, "maioria absoluta" poderia ser maioria absoluta dos votos. Aqui, Cavalcanti recorre a influentes comentadores da legislação sobre S.A., incluindo Modesto Carvalhosa, para afirmar que a doutrina não 
enxergava "maioria absoluta" em referência ao total dos membros presentes. Portanto, maioria absoluta dos votantes, pois maioria absoluta não diz nada sobre o quórum do qual retiraremos essa maioria, podendo ser dos votantes ou dos presentes.

Aliás, a Constituição dispunha da mesma forma em seu artigo 25 ("Os negócios se resolverão pela maioria absoluta de votos dos membros presentes.") e 50 ("As leis complementares somente serão aprovadas se obtiverem maioria absoluta dos votos dos membros das duas Casas do Congresso Nacional, observados os demais termos da votação das leis ordinárias"). Cavalcanti (2015) demonstra que o mesmo pleonasmo que Moreira Alves pensou enxergar no Art. 48 também poderia ser encontrada no Art. 18 da Constituição de 1891, no Art. 40 da Constituição de 1937, entre outras.

\section{Implicações: judicialização sem democratização?}

Do ponto de vista interno da argumentação constitucional, poucos são os aspectos que fogem da análise de Cavalcanti. Jurisprudência, texto constitucional, interpretação sistemática, comparações com outros países, doutrina - estão presentes muitos elementos típicos da argumentação jurídica, e todos parecem apontar no sentido defendido pelo autor. Como jurista, Cavalcanti estava mais interessado em notar possíveis incorreções na decisão da Suprema Corte e menos interessado em procurar as motivações e consequências dessa decisão. Sua análise profissional, porém, deixa evidente que o STF optou por um caminho tecnicamente improvável e difícil de sustentar, ignorando um claro precedente seu sobre a questão. O que quer se diga sobre as variáveis políticas na cabeça dos ministros ao adotarem a interpretação vitoriosa, é preciso reconhecer que ela foi profundamente transformadora do direito vigente. Representou uma reviravolta jurisprudencial. Em 1984, portanto, antes da democratização, o Tribunal exerceu um papel criativo no direito constitucional brasileiro, resolvendo em última instância uma questão política de grande voltagem para a conjuntura política nacional.

De fato, se não é possível afirmar, apenas pela análise dos argumentos constitucionais de Cavalcanti e do STF, que a decisão tinha motivações políticas específicas, ainda assim podemos observar os seus claros efeitos políticos. No caso, a forçada interpretação adotada pelo Tribunal não apenas ajudou a bloquear uma saída institucional possível para a transição para a democracia, como deu mais poder a um tipo de personagem político: o congressista ausente. Ao decidir que a contagem de votos para a aprovação da "PEC das Diretas" levava em consideração a totalidade dos membros da casa, e não dos presentes, o STF deu ao regime uma estratégia infalível para contornar aquela e outras situações que poderiam vir.

A mudança da forma de contagem do quórum adotada pelo STF alterou as regras do jogo de modo a dar mais poder, no Congresso, para blocos parlamentares minoritários que desejem bloquear mudanças com baixo risco de exposição. A partir dessa interpretação do STF, em vez de tentar votar contra, quem se opõe a uma determinada emenda constitucional poderia simplesmente não comparecer à sessão - ou seja, um tipo de estratégia política obstrucionista viabilizada por uma decisão judicial. O regime militar, assim, graças ao STF, passou a ter no esvaziamento da Câmara por seus apoiadores uma estratégia similar a um poder de veto, decisivo naquele momento de negociação da transição.

Ao fechar a possibilidade de que a abertura ocorresse por qualquer emenda constitucional minimamente controvertida no Congresso, o Supremo Tribunal Federal - por meio de uma interpretação criativa - deixou de uma vez por todas nas mãos do regime e em sua eficácia em controlar seus apoiadores a opção pela abertura. Mais do que uma saída conveniente de um imbróglio político em favor do governo em um impasse pontual, a decisão do Supremo foi, na prática, ela mesma, uma emenda à Constituição que aumentou o poder de veto do regime militar e seus apoiadores no Congresso.

Esse cenário, com o bloqueio judicial da aprovação da Emenda Dante de Oliveira, contém implicações mais amplas para estudos sobre a expansão do poder judicial nas democracias contemporâneas. A judicialização da política, o apelo às cortes e meios judiciais para encaminhar questões morais, de política pública e controvérsias políticas (HIRSCHL, 2010) é um dos fenômenos mais significantes dos governos do fim do século XX e início do XXI. No entanto, muitas vezes o conceito acaba abarcando diversas coisas, 
como a proliferação do discurso e jargões legais e a maior participação de cortes no desenho final de políticas públicas. Tratando, especificamente, do que chama de judicialização da "mega" política ou política "pura", Hirschl (2010) define o fenômeno como a transferência de assuntos contenciosos e litígios significativos de natureza política para as Cortes, como a judicialização de processos eleitorais, o escrutínio judicial das prerrogativas dos ocupantes do executivo quanto ao planejamento macroeconômico e previdência, etc.

A democracia tem sido observada como uma condição institucional necessária e facilitadora do fenômeno. Trabalhos como de Hirschl, porém, adotam como indicador a tomada de decisão judicial sobre questões que podemos chamar de substantiva e diretamente políticas. A pergunta levada ao conhecimento do STF é, em si, a mesma questão que os atores políticos procuram responder. Por esse critério, o caso das Diretas Já não nos permite dizer que o Supremo de fato decidiu a questão política da forma da transição brasileira para a democracia. Afinal, tratava-se de uma questão de determinação de qual quórum de votação deveria ser adotado - e não a constitucionalidade material da PEC. Nossa discussão desse caso, porém, aponta para a potencial insuficiência desse critério para mapear o poder que o Supremo pode exercer de fato: no caso, participou ativamente da construção de uma decisão política nacional sobre a transição por meio de uma decisão judicial que processual e indiretamente impactava na política. ${ }^{27}$ Portanto, em si, a questão jurídica levada ao Supremo poderia não aparecer no radar da judicialização da "mega-política" no sentido de Hirschl. Por trás da discussão procedimental, porém, a decisão na prática resolveu um conflito político substantivo fundamental.

\section{Conclusão}

Neste trabalho, procuramos mostrar que o caso das "Diretas Já" no STF possui todas as características típicas do processo de judicialização, ainda que tivesse por palco um regime ditatorial. No caso em questão, (i) um partido derrotado na arena política majoritária, o MDB, recorre ao STF para solucionar uma questão de natureza estritamente política, ou seja, se o quórum para aprovação de uma PEC havia sido alcançado; (ii) ao que tudo indica, o Tribunal utilizou seu poder de interpretação para alterar o sentido da constituição, ignorando os precedentes da própria Corte. Além disso, (iii) apesar de tecnicamente não ter exercido seu poder para anular a decisão congressual que considerou não aprovada a Emenda, a Corte contrariou seus precedentes para dar mais espaço de ação ao governo do momento.

Esse último elemento, na verdade, é bastante semelhante a diversas decisões do STF nos anos 90 , em que o Tribunal interpretou a constituição de forma criativa para reduzir seus próprios poderes em controle de constitucionalidade (ARGUELHES, 2014). Além disso, ao longo dos anos 90, o STF não chegou a utilizar, de forma clara e sistemática, o poder de que dispunha para declarar a inconstitucionalidade de programas políticos relevantes para o governo (OLIVEIRA, 2005) - e, ainda assim, mesmo sem um conjunto de decisões que, claramente, colocassem o Tribunal em rota de colisão com o governo, já se falava de judicialização da política no Brasil (p.ex., CASTRO, 1997). Nesse cenário, por que não pensar em diferenças mais sutis, de grau, entre o STF pré-democratização e o STF pós-democratização? Certamente, há diferenças entre os dois períodos em termos da extensão do poder do STF, das oportunidades de exercê-lo e dos temas que poderiam ser diretamente levados à corte. As continuidades, porém, podem ser muito maiores do que o pensamento constitucional convencional pós-1988 faz crer.

\section{Referências}

ARANTES, Rogério Bastos. Judiciário: entre a justiça e a política. In: AVELAR, Lúcia; CINTRA, Antônio Octávio. Sistema político brasileiro: uma introdução. São Paulo: Unesp, 2015. p. 81-115.

\footnotetext{
27 Ajurisprudência original do STF sobre o controle de constitucionalidade preventivo de emendas à constituição, por meio de mandados de segurança de parlamentares, também foi criada durante o regime militar e também utiliza o procedimento para controlar, na prática, o conteúdo. Na primeira decisão afirmando esse poder, no início dos anos 80 , o tribunal considerou que esse controle era na verdade procedimental, na medida em que a constituição de 1967 estabelecia que "não será objeto de deliberação" propostas que violassem cláusulas pétreas. Com isso, segundo o Supremo, abria-se uma porta para intervenção judicial durante o processo legislativo mesmo (SÜSSEKIND, 2014).
} 
ARGUELHES, Diego Werneck. Poder não é querer: preferências restritivas e redesenho institucional no Supremo Tribunal Federal pós-democratização. Universitas Jus, Brasília, v. 25, n. 1, p. 25-45, 2014.

ARGUELHES, Diego Werneck; RIBEIRO, Leandro Molhano. Criatura e/ou criador: transformações do Supremo Tribunal Federal sob a Constituição de 1988. Revista Direito GV, São Paulo, v. 12, n. 2, p. 405-440, 2016.

ARGUELHES, Diego Werneck; SÜSSEKIND, Evandro. Building judicial power in Latin America: Opposition strategies and the lessons of the Brazilian case. Revista Uruguaya de Ciencia Política, Montevideo, v. 27, n. 1, p.175-196, 2018.

BARROSO, Luís Roberto. Constituição, democracia e supremacia judicial: direito e política no Brasil contemporâneo. Revista Jurídica da Presidência, Brasília, v. 12, n. 96, p. 5-43, 2010.

BERTONCELO, Edison. A campanha das diretas e a democratização. São Paulo: Humanitas, 2007.

BERTONCELO, Edison. "Eu quero votar para presidente": uma análise sobre a Campanha das Diretas. Lua Nova: Revista de Cultura e Política, Curitiba, v. 76, p. 169-196, 2009.

CAVALCANTI, José Paulo. 1984: O Supremo, contra as diretas, emenda a Constituição. Revista de Direito Administrativo, Rio de Janeiro, v. 269, p. 377-416, 2015.

CARVALHO, Ernani. Revisão judicial e judicialização da política no direito ocidental. Revista de Sociologia e Política, Curitiba, n. 28, p. 161-179, 2007.

CASTRO, Marcus Faro de. O Supremo Tribunal Federal e a judicialização da política. Revista Brasileira de Ciências Sociais, São Paulo, v. 12, n. 34, p. 147-156, 1997.

DELGADO, Lucília de Almeida Neves. A campanha das Diretas Já: narrativas e memórias. São Paulo: Perseu Abramo, 2003.

DOTAN, Yoav; HOFNUNG, Menachem. Legal defeats - political wins why do elected representatives go to court? Comparative Political Studies, Sage Publications, v. 38, n. 1, p. 75-103, 2005.

ELSTER, Jon. Constitution-making in Eastern Europe: Rebuilding the Boat in the Open Sea. Public Administration, Cambridge, v. 71, n. 1-2, p. 169-217, 1993.

GINSBURG, Tom; MOUSTAFA, Tamir. Rule by law: the politics of courts in authoritarian regimes. New York: Cambridge University Press, 2008.

GINSBURG, Tom. Judicial review in new democracies: constitutional courts in Asian cases. New York: Cambridge University Press, 2003.

HIRSCHL, Ran. The Judicialization of politics. In: CALDEIRA, Gregory A.; R. KELEMEN, Daniel; WHITTINGTON, Keith E. (Ed.). The Oxford Handbook of Law and Politics. Oxford University Press, 2010. v. 3. p. 119-142.

HIRSCHL, Ran. Towards juristocracy: the origins and consequences of the new constitutionalism. Cambridge: Harvard University Press, 2004.

HIRSCHL, Ran. The new constitutionalism and the judicialization of pure politics worldwide. Fordham $\mathbf{L}$. Rev., Nova lorque, v. 75, n. 2, p. 721-753, 2006.

JUNQUEIRA, Eduardo. Reforma da Constituição de 1891. In: ABREU, Alzira Alves de (Org.). Dicionário da Elite Republicana (1891-1930). Rio de Janeiro: Centro de Pesquisa e Documentação de História Contemporânea do Brasil, 2001. Disponível em: <https://cpdoc.fgv.br/sites/default/files/verbetes/primeirarepublica/REFORMA\%20DA\%20CONSTITUI\%C3\%87\%C3\%83O\%20DE\%201891.pdf>. Acesso em: 12 set. 2017.

LEAL, Fernando. Uma jurisprudência que serve para tudo. In: FALCÃO, Joaquim; ARGUELHES, Diego W.; RECONDO, Felipe (Org.). O Supremo em 2015. Rio de Janeiro: FGV, 2016. p. 207-209.

LEAL, Fernando. Prisão em segunda instância: o STF vítima de si mesmo. JOTA, São Paulo, 26 maio 2017. Disponível em: <https://jota.info/colunas/supra/prisao-em-segunda-instancia-o-stf-vitima-de-simesmo-26052017>. Acesso em: 12 set. 2017. 
LYNCH, Christian Edward Cyril; MENDONCA, José Vicente Santos de. Por uma história constitucional brasileira: uma crítica pontual à doutrina da efetividade. Revista Direito \& Práxis, Rio de Janeiro, v. 8, n. 2, p. 974-1007, 2017.

MACIEL, Débora Alves; KOERNER, Andrei. Sentidos da judicialização da política: duas análises. Lua Nova, São Paulo, n. 57, p. 113-133, 2002.

MOUSTAFA, Tamir. The struggle for constitutional power: law, politics, and economic development in Egypt. New York: Cambridge University Press, 2007.

OLIVEIRA, Vanessa Elias. Judiciário e privatizações no Brasil: existe uma judicialização da política? Revista de Ciências Sociais, Rio de Janeiro, v. 48, n. 3, p. 559-587, 2005.

OSIEL, M. J. Dialogue with dictators: Judicial resistance in Argentina and Brazil. Law \& Social Inquiry, Cambridge, v. 20, n. 2, p. 481-560, 1995.

PEREIRA, A. W. Political (in)justice: Authoritarianism and the Rule of Law in Brazil, Chile, and Argentina. Pittsburgh: University of Pittsburgh Press, 2005.

PEREIRA, Anthony W. Of judges and generals: security courts under authoritarian regimes in Argentina, Brazil, and Chile. In: GINSBURG, Tom; MOUSTAFA, Tamir (Ed.). Rule by law: the politics of courts in authoritarian regimes. Cambridge: Cambridge University Press, 2007. p. 23-57.

PERTENCE, J. P. S. O controle de constitucionalidade das emendas constitucionais pelo Supremo Tribunal Federal: crônica de jurisprudência. Revista Eletrônica de Direito do Estado (REDE), Salvador, n. 9, 2007.

RODRIGUES, Alberto Tosi. Diretas Já - O grito preso na garganta. São Paulo: Fundação Perseu Abramo, 2003.

ROLDAN, Andrés Del Río. El desarrollo Institucional de la Corte Suprema de Justicia Nacional y del Supremo Tribunal Federal: trayectorias comparadas desde el estableciemiento a la democratización. Curitiba: CVR, 2014.

SWEET, Alec Stone. Judicialization and the construction of governance. Comparative Political Studies, Sage Publications, v. 32, n. 2, p. 147-184, 1999.

TATE, C. Neal. The global expansion of judicial power. New York: NYU Press, 1995.

TAYLOR, Matthew M.; DA ROS, Luciano. Os partidos dentro e fora do poder: a judicialização como resultado contingente da estratégia política. Dados - Revista de Ciências Sociais, Rio de Janeiro, v. 51, n. 4, p. 825-864, 2017. Disponível em: <http://www.redalyc.org/articulo.oa?id=21817687002>. Acesso em: 12 set. 2018.

TAYLOR, Matthew. Judging policy: courts and policy reform in democratic Brazil. Stanford: Stanford University Press, 2008.

VALLINDER, Torbjörn; TATE, C. Neal. Global expansion of judicial power. New York: New York University Press, 1995.

VIANNA, Luiz Werneck. A judicialização da política e das relações sociais no Brasil. Rio de Janeiro: Revan, 1999.

VOJVODIC, Adriana de Moraes; MACHADO, Ana Mara França; CARDOSO, Evorah Lusci Costa. Escrevendo um romance, primeiro capítulo: precedentes e processo decisório no STF. Revista Direito GV, São Paulo, v. 5, n. 1, p. 21-44, 2009.

WHITTINGTON, Keith E. "Interpose your friendly hand": Political supports for the exercise of judicial review by the United States Supreme Court. American Political Science Review, Cambridge University Press, v. 99, n. 4, p. 583-596, 2005. 